\title{
IVIVC for Extended Release Hydrophilic Matrix Tablets in Consideration of Biorelevant Mechanical Stress
}

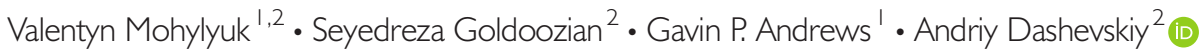

Received: 17 July 2020 / Accepted: 28 September 2020 / Published online: 22 October 2020

(C) The Author(s) 2020

\begin{abstract}
Purpose When establishing IVIVC, a special problem arises by interpretation of averaged in vivo profiles insight of considerable individual variations in term of time and number of mechanical stress events in GI-tract. The objective of the study was to investigate and forecast the effect of mechanical stress on in vivo behavior in human of hydrophilic matrix tablets.
\end{abstract}

Methods Dissolution profiles for the marketed products were obtained at different conditions (stirring speed, single- or repeatable mechanical stress applied) and convoluted into C-t profiles. Vice versa, published in vivo $\mathrm{C}$-t profiles of the products were deconvoluted into absorption profiles and compared with dissolution profiles by similarity factor.

Results Investigated hydrophilic matrix tablets varied in term of their resistance against hydrodynamic stress or single stress during the dissolution. Different scenarios, including repeatable mechanical stress, were investigated on mostly prone Seroquel ${ }^{\circledR}$ XR $50 \mathrm{mg}$. None of the particular scenarios fits to the published in vivo C-t profile of Seroquel ${ }^{\circledR}$ XR $50 \mathrm{mg}$ representing, however, the average of individual profiles related to scenarios differing by number, frequency and time of contraction stress. When different scenarios were combined in different proportions, the profiles became closer to the original in vivo profile including a burst between 4 and $5 \mathrm{~h}$, probably, due to stress-events in GI-tract.

Conclusion For establishing IVIVC of oral dosage forms susceptible mechanical stress, a comparison of the deconvoluted individual in vivo profiles with in vitro profiles of different dissolution scenarios can be recommended.

Andriy Dashevskiy

a.dashevskiy@fu-berlin.de

Pharmaceutical Engineering Group, School of Pharmacy, Queen's University Belfast, 97 Lisburn Road, Belfast BT9 7BL, UK

2 College of Pharmacy, Freie Universität Berlin, Kelchstrasse 31, 12169 Berlin, Germany
KEY WORDS extended release - gastrointestinal contraction · hydrophilic matrix tablet · IVIVC · pharmacokinetic profile

\section{ABBREVIATIONS \\ Gl Gastrointestinal \\ C-t Concentration-time \\ IVIVC In vitro - in vivo correlation}

\section{INTRODUCTION}

In addition to being used to understand oral bioavailability, in vitro - in vivo correlation (IVIVC) is being increasingly applied in the development of controlled release oral dosage forms. For example, an important and extensive cross-organization collaborative project involving multidisciplinary partners (OrBiTo) has examined important physicochemical properties of active pharmaceutical ingredients, in vitro characterization of drug formulations, characterization of in vivo behavior of compounds and formulations in GI-tract as well as in-silico models in developing oral dosage forms (1).

Recently, the effect of simulated GI-stress during dissolution from an extended release matrix tablet has been investigated using a specially adapted dissolution apparatus including different load cells (2-8), in-house dissolution testing apparatus (9-11), and periodical loading of dosage forms outside of the dissolution vessel $(12,13)$. Commonly, a single mechanical stress event e.g. $300 \mathrm{mbar}(3,6), 300 \mathrm{~g} / \mathrm{cm}^{2}$ (13) or $400 \mathrm{~g}$ (10) during physiologically-relevant dissolution tests was applied in order to replicate as best as possible in vivo data obtained with SmartPill ${ }^{\circledR}(14)$. Using an alternative approach, a "destructive force dependent release system" (15), the maximum stomach and small intestine contraction force were 
utilized and determined at the level of approximately $1.9 \mathrm{~N}$ (16) and 1.2 $\mathrm{N}(17)$, respectively.

The transportation of tablet along the GI-tract is highly unpredictable with relatively high intra- and interindividual variability. Generally agreed periodicity of stomach emptying via migrating myoelectric is $<120 \mathrm{~min}$, however, it is not entirely predictable (18) due to, for example, a retro-propulsion back into the stomach of non-disintegrated dosage forms (19). The mechanical stress-events in the stomach and intestine can depend on many factors including individual physiological features, type of physical activity, lifestyle, and type of consumed food/drink (20). Also data regarding the effects of tablet size on stomach transit are conflicting $(21,22)$. Thus, the behavior of a non-disintegrating tablet in GI-tract is unique in terms of residence time in different parts of GI-tract, the effect of different media, agitation level and number and severity of stress-events.

The importance of predictive dissolution testing is continuously increasing because of the possibility of pharmacokinetic modelling and deeper understanding of different factors affecting drug absorption in viwo (23). For this purpose, in vivo C-t profiles can be deconvoluted to an absorption profile and then compared to dissolution profiles (24). Because the dissolution is the rate-determining step for extended release dosage forms, a correlation of dissolution profile to absorption profile is justified (25). On another hand, dissolution profiles can be convoluted into $\mathrm{C}$-t profiles and then compared with in vivo $\mathrm{C}$-t profiles (24). One problem associated with both approaches is the relatively high spread on the individual in vivo data leading to misinterpretation based on averaged C-t profiles which represent the mean of different scenarios predetermined by level, number and frequency of the stress which varies in different parts of the GI-tract (14-17). Therefore, the comparison of either single or averaged in vivo with in vitro profiles would be preferable (26). Unfortunately, in most cases, individual C-t profiles are available only for sponsors of bioequivalence trials at fasting conditions, and generally available data often presents only averaged (geometric mean) profiles. Only a limited number of available sources allow an insight into original single $\mathrm{C}$-t profiles and their variability e.g. a bioequivalence study with Seroquel® XR $300 \mathrm{mg}(27)$.

Thus, it appears difficult to fit a specific dissolution scenario to averaged data. More logically it would be rational to generate dissolution profiles under different dissolution conditions, which mimic reasonable individual GI scenarios, and then convert them into predicted individual C-t profiles. Averaged predicted C-t profiles can be achieved by balancing of individual profiles in proportions reflecting the probability of the corresponding scenarios in vivo.

Since swellable/erodible hydrophilic tablets are considered as highly vulnerable to the mechanical stress, the objective of this study was to assess the effect of mechanical stress events in different dissolution scenarios and the impact that may have upon the prediction of in vivo profiles for different hydrophilic matrix tablets.

\section{MATERIALS AND METHODS}

\section{Materials}

Commercial products Tromphyllin ${ }^{\circledR}$ retard $300 \mathrm{mg}$ (Trommsdorff GmbH \& Co. KG, Alsdorf, Germany), Glucophage ${ }^{\circledR}$ XR 500 mg (Merck Serono GmbH, Darmstadt, Germany), Alfuzosin-ratiopharm ${ }^{\circledR}$ uno $10 \mathrm{mg}$ (Ratiopharm GmbH, Ulm, Germany), Seroquel ${ }^{\circledR}$ XR $50 \mathrm{mg}$ (AstraZeneca GmbH, Wedel, Germany) and Preductal ${ }^{\circledR}$ MR 35 mg (Les Laboratories Servier, Gidy, France) were used. Chemicals used for preparation of dissolution media were of Pharmacopoeia grade and used as received.

\section{Dissolution}

Since investigated extended-release hydrophilic matrix tablets supposed to release most of the active substance in the intestinal environment, USP phosphate buffer solution $\mathrm{pH}$ of 6.8 was used as the main dissolution medium. Dissolution testing was conducted using an USP Apparatus II (28) with a paddle agitation speed of 50, 100 or $150 \mathrm{rpm}$ (VK 7000, VanKel Industries, NJ, USA) in $900 \mathrm{~mL}$ dissolution medium (29). If specified, at predetermined time-points (as after 1, 2 and $4 \mathrm{~h}$ ) tablets were withdrawn together with $6 \mathrm{~mL}$ of medium, placed in Petri dishes and subjected to $2 \mathrm{~N}$ mechanical loading for 60 s using a texture analyzer (TA.XTplus, Stable Micro Systems Ltd., UK) equipped with a flat-faced cylindrical probe with a diameter of $20 \mathrm{~mm}$. After that, tablets were immediately placed back in the dissolution vessel and residuals in the Petri dishes were rinsed with $5 \mathrm{~mL}$ of medium to continue the dissolution test. During the dissolution test, samples were taken at predetermined time-points: for Tromphyllin ${ }^{\circledR}$ retard 300, Glucophage $\AA$ XR 500 mg - every 30 min during the first $6 \mathrm{~h}$ and then every hour; Alfuzosin-ratiopharm $\AA$ uno $10 \mathrm{mg}$ - every $30 \mathrm{~min}$ during the first hour and then every hour; Seroquel ${ }^{\circledR}$ XR $50 \mathrm{mg}$ - at 15, 30, 60, 90, $120 \mathrm{~min}$ and then every hour; and Preductal ${ }^{\circledR}$ MR $35 \mathrm{mg}$ - every $30 \mathrm{~min}$ during the first $7 \mathrm{~h}$ and then every hour. The schedule of mechanical stress loading was the same, but the sampling plan was for every commercial product individual because of the different duration and $\mathrm{T}_{\max }$. Samples were filtered through a $0.22 \mu \mathrm{m}$ filters and active substances were quantified using UV-spectroscopy (HP 8453, Agilent Technologies GmbH, Germany) with following parameters: theophylline $-\lambda=$ $271 \mathrm{~nm}, \mathrm{C}=17.62^{*} \mathrm{~A}, \mathrm{r}^{2}=0.9993$; metformin $\lambda=234 \mathrm{~nm}$, $\mathrm{C}=14.64^{*} \mathrm{~A}, \mathrm{r}^{2}=0.9997$, alfuzosin $-\lambda=245 \mathrm{~nm}, \mathrm{C}=$ 
$9.11 * \mathrm{~A}+0.0447, \mathrm{r}^{2}=0.9998$, trimetazidine dihydrochloride $-\lambda=269 \mathrm{~nm}, \mathrm{C}=45.46 * \mathrm{~A}, \mathrm{r}^{2}=0.9999$, quetiapine fumarate $\lambda=290 \mathrm{~nm}, \mathrm{C}=58.14^{*} \mathrm{~A}, \mathrm{r}^{2}=0.9999$. Drug release $(\%)$, presented as a mean of six parallel measurements, was plotted versus time.

\section{Deconvolution and Convolution}

Published original single dose C-t profile of Glucophage® XR $500 \mathrm{mg}$ (30), Alfuzosin-ratiopharm ${ }^{\circledR}$ uno $10 \mathrm{mg}(31)$, Tromphyllin ${ }^{\circledR}$ retard $300 \mathrm{mg}$ (31) Preductal ${ }^{\circledR}$ MR $35 \mathrm{mg}$ (32) and Seroquel® XR $50 \mathrm{mg}$ (31) at fasting conditions have been shown to follow a one compartmental distribution model and, therefore, deconvoluted using the Wagner-Nelson equation (Eq. 1) (33, 34) and experimental dissolution profiles were convoluted into $\mathrm{C}$-t profiles using the following equation (Eq. 2) $(33,34)$

$$
\begin{aligned}
F(\%) & =\frac{C_{p}+k_{e l} A U C_{0-t}}{k_{e l} A U C_{i n f} .} \\
C_{p+1} & =\frac{\frac{2 \cdot \Delta F \cdot D}{V_{d}}+C_{p} \cdot\left(2-k_{e l} \cdot \Delta t\right)}{\left(2-k_{e l} \cdot \Delta t\right)}
\end{aligned}
$$

where: $\mathrm{F}$ is cumulative fraction of drug absorbed at time $\mathrm{t} ; \mathrm{C}_{\mathrm{p}}$ is the plasma concentration of drug at time $\mathrm{t} ; k_{e l}=\ln 2 / t_{1 / 2}$ is the elimination rate constant; $\mathrm{AUC}_{0-\mathrm{t}}$ is the area under the plasma concentration-time $(\mathrm{C}$-t $)$ profile until time $\mathrm{t}$; $\mathrm{D}$ is a dose corrected on bioavailability; and $\mathrm{V}_{\mathrm{d}}$ is apparent volume distribution.

\section{Profile Comparison}

For comparison of profiles the similarity factor (f2) was calculated using the following equation:

$f 2=50 \cdot \log \left(\left[1+\frac{1}{n} \sum\left(C_{\text {diss. }}-C_{\text {abs. }}\right)^{2}\right]^{-0.5} \times 100\right)$

where $C_{d i s s}$ represents data from dissolution profiles achieved experimentally at different conditions and $C_{a b s \text {. }}$ - data from absorption profiles achieved by deconvolution of published original profiles.

Similarity factors, for each investigated product, achieved for dissolution profiles at a different stirring speed vs. absorption profile were compared with each other by calculation of a difference between the maximal $\mathrm{f} 2_{\max }$ value in the set and $\mathrm{f} 2_{\mathrm{i}}$ of interest. The extent and direction of change in dissolution profiles upon single stress were expressed by a difference between $\mathrm{f}_{\text {stress }}$ and $\mathrm{f} 2$ no stress. Alternatively, linear regression analysis was applied to the in vitro-in vivo correlation plots and the coefficient of determination $\left(\mathrm{r}^{2}\right)$ was calculated using the following equation: $r^{2}=\left(\frac{n \sum\left(x_{i} y_{i}\right)-\sum x_{i} \sum y_{i}}{\sqrt{\left[n \sum\left(x_{i}^{2}\right)-\left(\sum x_{i}\right)^{2}\right] \cdot\left[n \sum\left(y_{i}^{2}\right)-\left(\sum y_{i}\right)^{2}\right]}}\right)^{2}$

where: $x_{i}$ - fraction dissolved and $y_{i}$ fraction absorbed at respective time points.

\section{RESULTS}

For comparison of release and deconvoluted curves, the correlation coefficient (r2), the similarity factor (f2), the mean dissolution time (MDT) or, for comparison of in viwo and convoluted release curves, the AUC are usually used. MDT is an integral parameter hiding essential information about shape of dissolution profile. A precise calculation of AUC in this study was, unfortunately, not possible because the in vivo data available (only partially) in the literature were used. Therefore, the correlation coefficient and similarity factor were applied for comparison of the dissolution and deconvoluted in vivo profiles.

\section{Effect of Hydrodynamic Conditions}

To investigate the effect of paddle stirring speed, the f 2 value for dissolution profiles at stirring speed 50, 100 and $150 \mathrm{rpm}$ vs. corresponding absorption profile (deconvoluted published profiles) were calculated. Drug release from Glucophage $\mathbb{R}$ $\mathrm{XR}$ and Preductal ${ }^{\circledR}$ MR was not affected by paddle stirring speed in the range 50-150 rpm (Fig. la and c). The $\mathrm{f} 2$ was in a range 46.6-49.3 and 50.6-57.4 for Glucophage ${ }^{\circledR} \mathrm{XR}$ and Preductal ${ }^{\circledR}$ MR, respectively (Table I). For the discrimination of existing differences between particular dissolution profiles, the $\mathrm{f} 2$ factor seems to be more powerful than $\mathrm{r}^{2}$ - coefficient of determination (Table I), which is, however, mostly used for quantification of IVIVC (35). A moderate effect of paddle stirring speed on drug release was observed for Alfuzosinratiopharm $\AA$ and Tromphyllin $\AA$ retard (Fig. 1e and g). For Alfuzosin-ratiopharm ${ }^{\circledR}$, the $\mathrm{f} 2$ increased (47.1, 49.2 and 59.2) with increasing the stirring speed (50, 100 and $150 \mathrm{rpm})$, respectively (Table I). For Tromphyllin $\AA$, the dissolution profile at $100 \mathrm{rpm}$ showed the greatest similarity with absorption profile ( $\mathrm{f} 2=65.7)$, followed by dissolution profile at $150 \mathrm{rpm}$ $(\mathrm{f} 2=61.0)$ and $50 \mathrm{rpm}(\mathrm{f} 2=44.3)($ Fig. $1 \mathrm{~g}$, Table I).

Dissolution profiles of Seroquel ${ }^{\circledR}$ XR demonstrated the highest discrepancy in release at different paddle stirring speed (Fig. 1i). The $\mathrm{f} 2$ for comparison of dissolution/absorption profiles was rather low but increased $(21.4,27.7$ and 35.1) with increasing the stirring speed (50, 100 and $150 \mathrm{rpm}$ ), respectively (Table I). Also, the shape of dissolution and absorption profiles differed considerably. Namely, dissolution profiles 

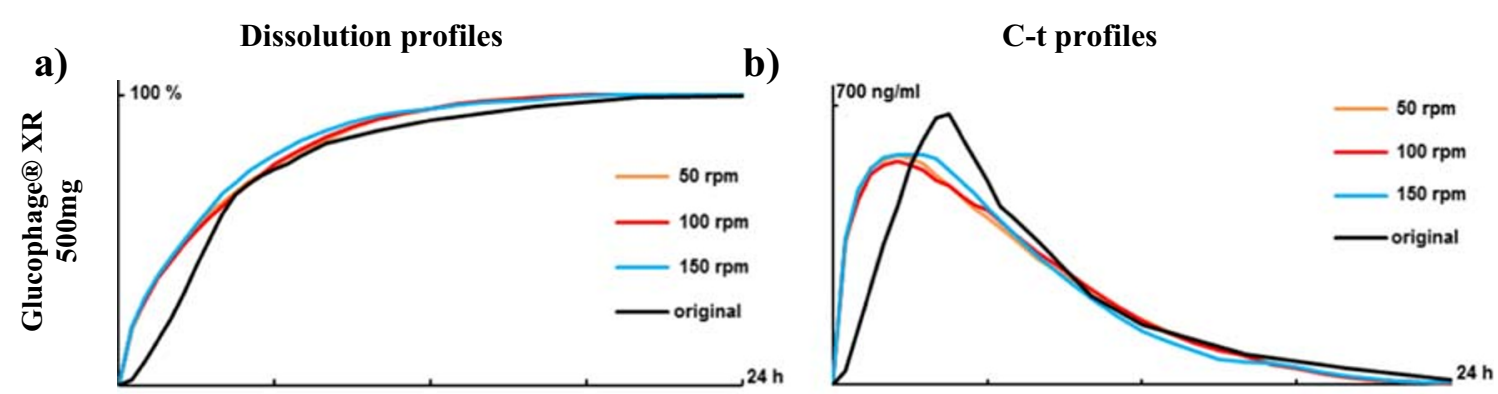

c)

d)
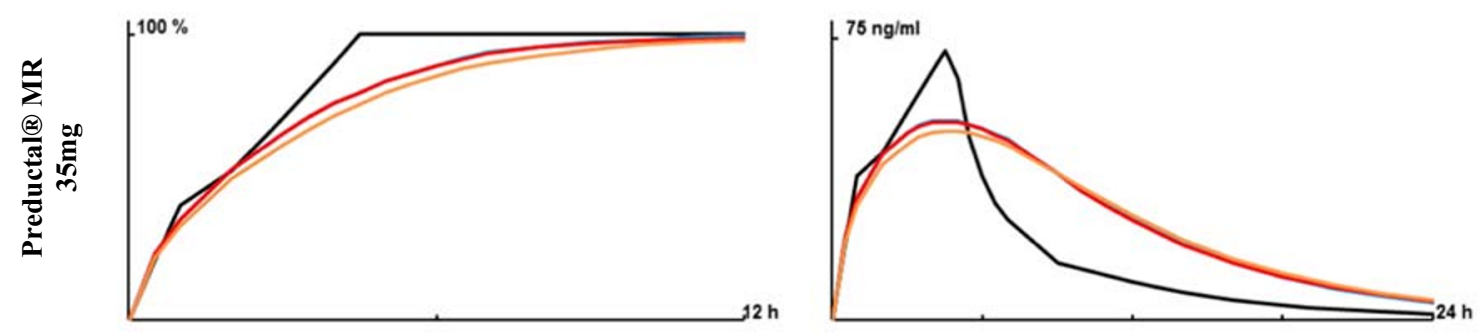

e)

f)
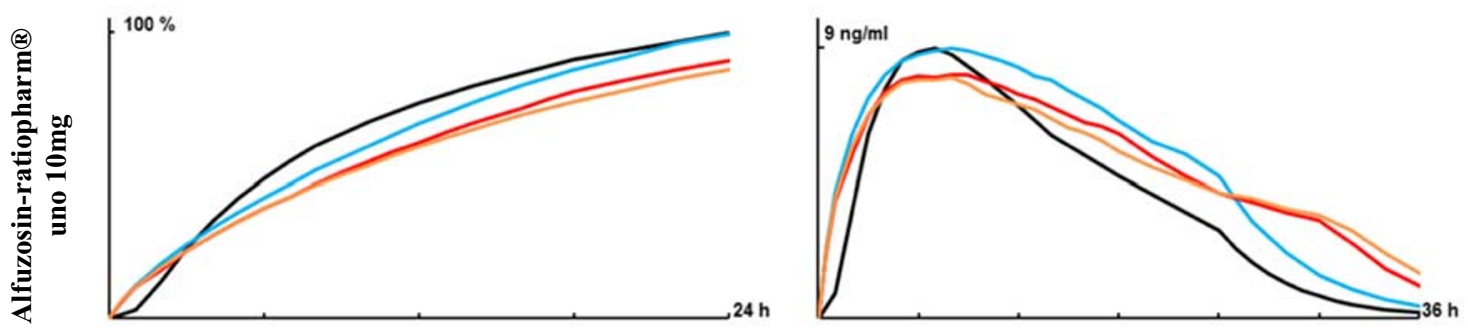

g)

h)
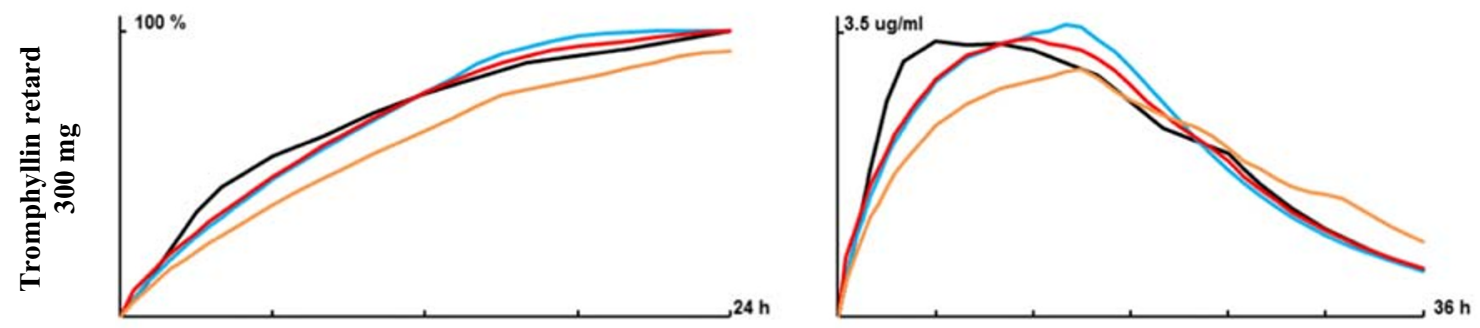

i)

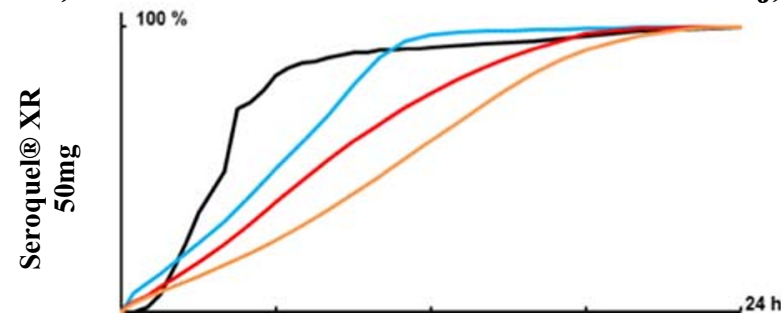

j)

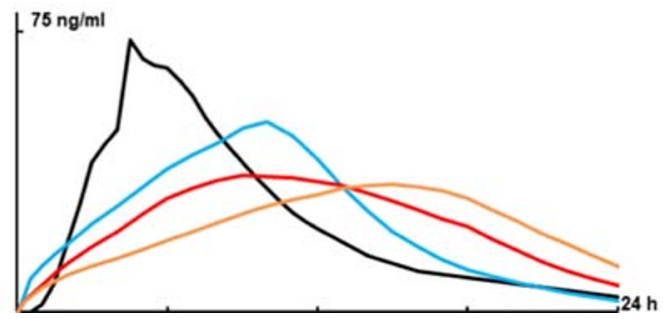

Fig. I (a, c, e, $\mathbf{g}$ and i) Dissolution profiles at stirring speed in phosphate buffer pH 6.8 in comparison with deconvoluted original C-t profiles. (b, d, f, $\mathbf{h}$ and $\mathbf{j}$ ) convoluted profiles at respective dissolution condition in comparison with original C-t profiles. (a and b) Glucophage ${ }^{\circledR}$ XR 500 mg, (c and d) Preductal ${ }^{\circledR}$ MR $35 \mathrm{mg}$, (e and f) Alfuzosin-ratiopharm $\AA$ uno $10 \mathrm{mg}$, (g and h) Tromphyllin ${ }^{\circledR}$ retard $300 \mathrm{mg}$ and $(\mathbf{i}$ and $\mathbf{j})$ Seroquel ${ }^{\circledR}$ XR $50 \mathrm{mg}$. SD has been waived for clarity of graphs.

were continuous, while a pronounced lag time followed by steep rise was observed on absorption profile (Fig. li) which was derived from a sharp peak at $4.5 \mathrm{~h}$ on original in vivo $\mathrm{C}-\mathrm{t}$ profile (Fig. 1j). 
Table I Similarity Factor (\%) Comparing Absorption Profiles with Dissolution Profiles at Different Stirring Speed or Mechanical Stress

\begin{tabular}{|c|c|c|c|c|c|c|c|c|}
\hline \multirow[t]{2}{*}{ Products } & \multicolumn{4}{|c|}{ Stirring speed } & \multicolumn{4}{|c|}{ Mechanical stress } \\
\hline & rpm & $\mathrm{f} 2$ & $f 2_{\max }-f z_{i}^{*}$ & $r^{2}$ & Stress after & $f 2$ & $f 2_{\text {stress }}-f 2_{\text {no stress }}{ }^{* *}$ & $r^{2}$ \\
\hline \multirow[t]{3}{*}{ Glucophage XR 500 mg } & 50 & 48.3 & 1.0 & 0.990 & $\mathrm{I} h$ & 47.3 & -2.0 & 0.993 \\
\hline & 100 & 49.3 & 0.0 & 0.990 & $2 \mathrm{~h}$ & 49.2 & -0.1 & 0.993 \\
\hline & 150 & 46.6 & 2.7 & 0.995 & $4 \mathrm{~h}$ & 47.7 & -1.6 & 0.993 \\
\hline \multirow[t]{3}{*}{ Preductal MR 35 mg } & 50 & 50.6 & 6.8 & 0.988 & $\mathrm{I} h$ & 63.4 & 6.2 & 0.975 \\
\hline & 100 & 57.2 & 0.2 & 0.987 & $2 \mathrm{~h}$ & 67.9 & 10.7 & 0.984 \\
\hline & 150 & 57.4 & 0.0 & 0.987 & $4 \mathrm{~h}$ & 56.4 & -0.8 & 0.991 \\
\hline \multirow[t]{3}{*}{ Alfuzosin-ratiopharm uno $10 \mathrm{mg}$} & 50 & 47.1 & 12.1 & 0.989 & I h & 52.5 & 3.3 & 0.989 \\
\hline & 100 & 49.2 & 10.0 & 0.987 & $2 \mathrm{~h}$ & 55.9 & 6.7 & 0.991 \\
\hline & 150 & 59.2 & 0.0 & 0.987 & $4 \mathrm{~h}$ & 59.5 & 10.3 & 0.990 \\
\hline \multirow[t]{3}{*}{ Tromphyllin retard $300 \mathrm{mg}$} & 50 & 44.3 & 21.4 & 0.981 & $\mathrm{Ih}$ & 56.3 & -9.4 & 0.989 \\
\hline & 100 & 65.7 & 0.0 & 0.992 & $2 \mathrm{~h}$ & 59.3 & -6.4 & 0.990 \\
\hline & 150 & 61.0 & 4.7 & 0.990 & $4 \mathrm{~h}$ & 59.6 & -6.1 & 0.990 \\
\hline \multirow[t]{3}{*}{ Seroquel ${ }^{\circledR}$ XR 50 mg } & 50 & 21.4 & 13.7 & 0.581 & I h & 34.6 & 6.9 & 0.864 \\
\hline & 100 & 27.7 & 7.4 & 0.759 & $2 \mathrm{~h}$ & 36.8 & 9.1 & 0.893 \\
\hline & 150 & 35.1 & 0.0 & 0.853 & $4 \mathrm{~h}$ & 43.9 & 16.2 & 0.925 \\
\hline
\end{tabular}

* $\mathrm{f}_{\text {max }}-\mathrm{f} \mathrm{2}_{\mathrm{i}}$ - the difference between maximal $\mathrm{f} 2$ value in the set and $\mathrm{f} 2$ of interest,

*** $\mathrm{Z}_{\text {stress }}-\mathrm{f} \mathrm{Z}_{\mathrm{no}}$ stress - the difference between $\mathrm{f} 2$ for dissolution at $100 \mathrm{rpm}$ with particular stress and without stress, respectively

\section{Effect of Single Mechanical Stress Event}

To investigate the effect of a single mechanical stress event on dissolution, tablets were subjected to $2 \mathrm{~N}$ mechanical loading for $60 \mathrm{~s}$ after 1, 2 or $4 \mathrm{~h}$. Under these conditions, dissolution profiles of Glucophage ${ }^{\circledR}$ XR, Alfuzosin-ratiopharm ${ }^{\circledR}$ and Tromphyllin ${ }^{\circledR}$ retard demonstrated relatively low changes (Fig. 2). Accordingly, convoluted C-t profiles had similar trends, although did not match the original profiles (Fig. 2). Consequently, f2 values for profiles with single stress events after 1, 2 and $4 \mathrm{~h} v s$. non-stressed profiles changed only slightly (Table I).

For Preductal ${ }^{\circledR}$ MR and Seroquel ${ }^{\circledR}$ XR, each individual stress event caused a burst release. The most pronounced burst release was after mechanical stress at $4 \mathrm{~h}$ (Fig. 2c and i). Thus, for Preductal ${ }^{\circledR}$ MR, convoluted C-t profile matched well the original in term of $\mathrm{t}_{\max }$ (approx. $4.5 \mathrm{~h}$ ) unlike Cmax which was below of original (Fig. 2d). The highest burst release after $4 \mathrm{~h}$ was also in case of Seroquel ${ }^{\circledR} \mathrm{XR}$. The convoluted C-t profile with applied stress at $4 \mathrm{~h}$ was closest to original in term of Cmax but 1.5-2.5 h delayed (Fig. 2j).

\section{Effect of Repeatable Mechanical Stress Events}

Dissolution tests with repeatable mechanical stress events were performed with Seroquel ${ }^{\circledR}$ XR matrix tablets since they were most affected by mechanical stress. The highest $\mathrm{f} 2$ value $(59.7 \%)$ was obtained using phosphate buffer solution
pH 6.8 at $100 \mathrm{rpm}$ and consequent stress application after 1, 2 and $4 \mathrm{~h}$ (Fig. 3a). Due to application of repeatable stress in the time range $1-4 \mathrm{~h}, \mathrm{C}$-t profiles became closer in the shape to the original (Fig. 3).

\section{Combination of Convoluted C-T Profiles}

In order to mimic data aggregation within one bioequivalence study, profiles according to 5 different in vitro dissolution scenarios (Fig. 4, Table II) were convoluted and combined in different ratios to create weighted averaged C-t profile. Generally, the shape of these profiles was closer to the original profile except for the difference in a lag-time (Fig. 4). The lagtime of the original profiles can be attributed to a gradual transport of gastric liquid with dissolved drug towards the small intestine before absorption. This transport was not considered by direct convolution.

\section{DISCUSSION}

All chosen commercial products differ in type and concentration of hypromellose, as a matrix-forming agent, weight, and shape of the tablets (36). One of the most common methods to investigate the robustness of swellable/ erodible matrix tablets towards mechanical stress in the GI-tract can be dissolution testing under increased stirring speed (37). Generally, the best similarity of absorption and 


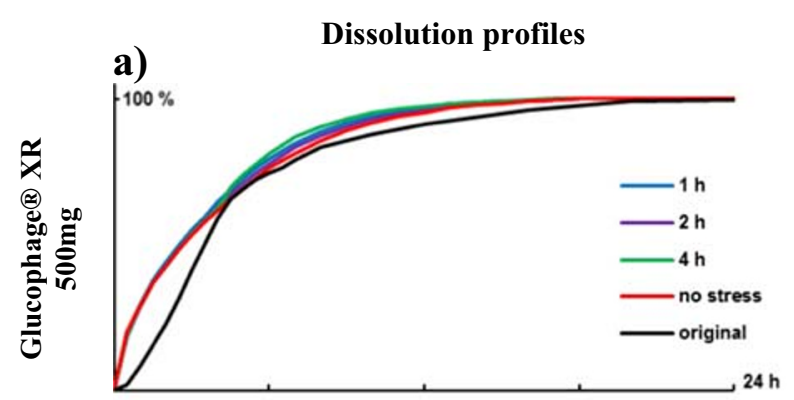

c)

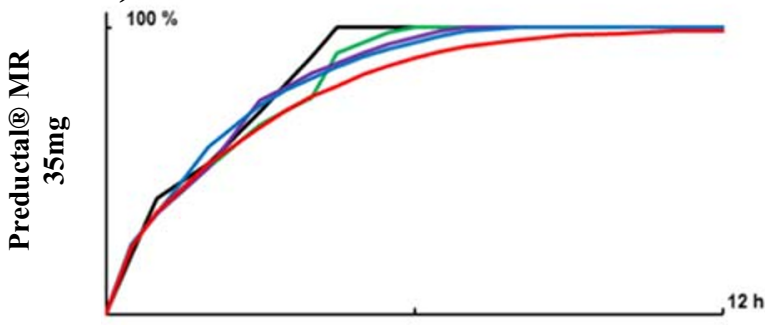

e)

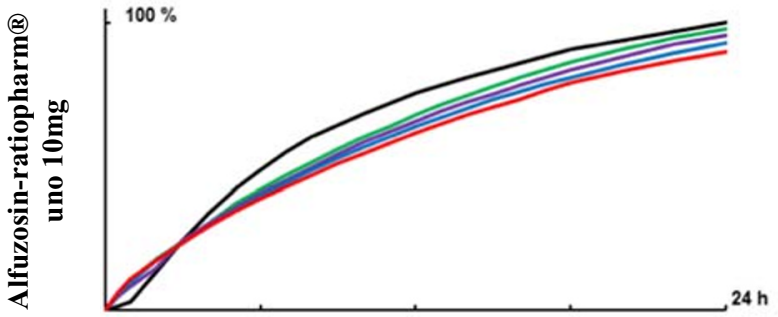

g)

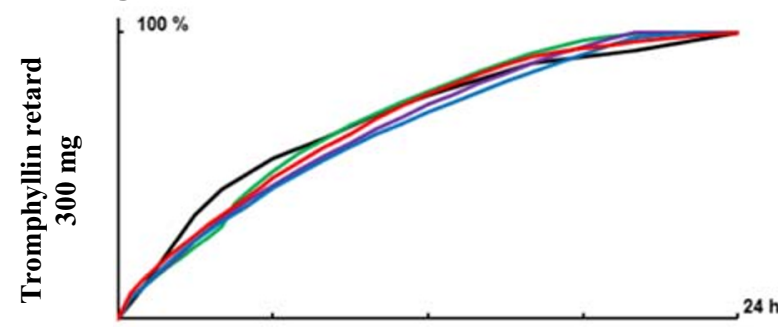

i)

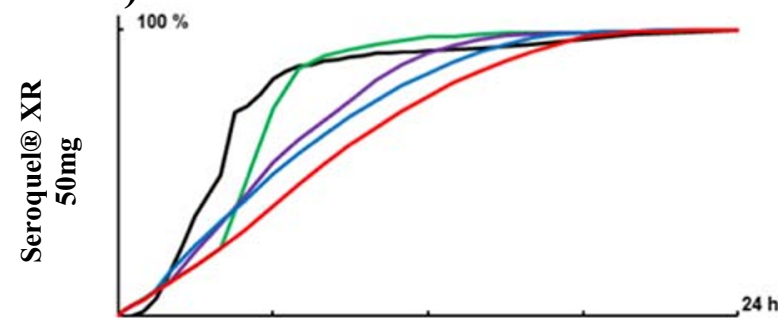

b) C-t profiles

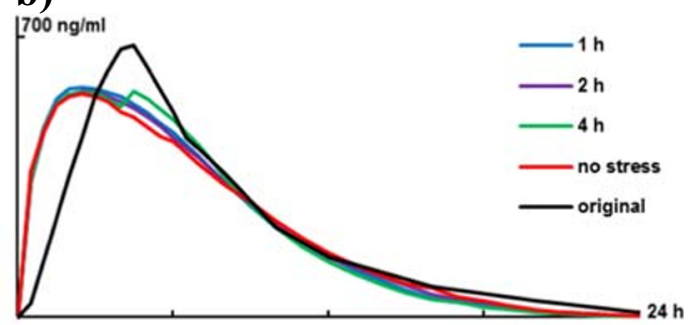

d)

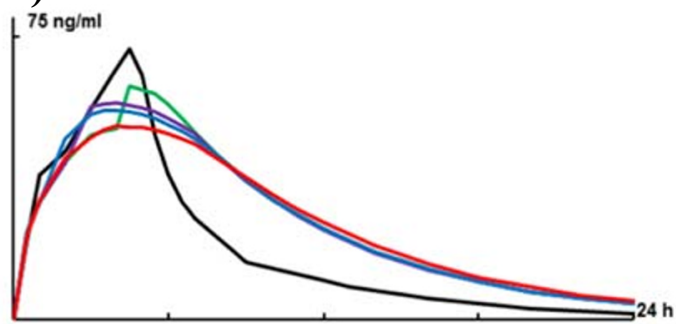

f)

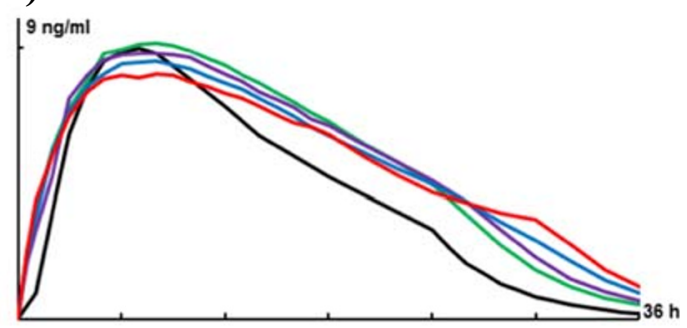

h)

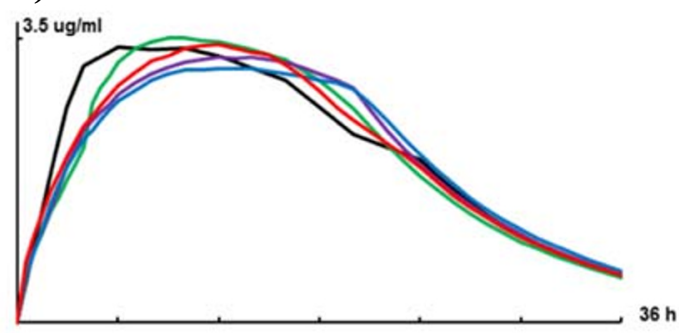

j)

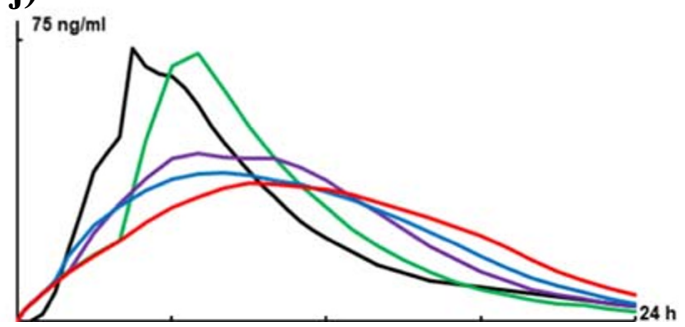

Fig. 2 (a, c, e, $\mathbf{g}$ and i) Dissolution profiles at I $00 \mathrm{rpm}$ in phosphate buffer $\mathrm{pH} 6.8$ and applied stress after I, 2 or $4 \mathrm{~h}$ in comparison with deconvoluted original C-t profiles. (b, d, $\mathbf{f}, \mathbf{h}$ and $\mathbf{j}$ ) convoluted profiles at respective dissolution condition in comparison with the original C-t profile. (a and $\mathbf{b}) \mathrm{Glucophage}{ }^{\circledR} \times \mathrm{R}$ 500 mg, (c and d) Preductal ${ }^{\circledR}$ MR 35 mg, E and F) Alfuzosin-ratiopharm ${ }^{\circledR}$ uno 10 mg, (g and h) Tromphyllin ${ }^{\circledR}$ retard 300 mg and (i and j) Seroquel ${ }^{\circledR}$ XR $50 \mathrm{mg}$. SD has been waived for clarity of graphs.

dissolution profiles was at higher stirring speed e.g. 100 or $150 \mathrm{rpm}$ (Table I). General pharmacopeial dissolution test for tablets with USP Apparatus II recommends stirring speed $50 \mathrm{rpm}$, probably, not sufficiently mimicking the in vivo hydrodynamics which is especially critical for hydrophilic matrix tablets.

Further source of mechanical stress on dosage forms in the GI-tract are periodic contractions in stomach and intestine 


\section{a) Dissolution profiles}

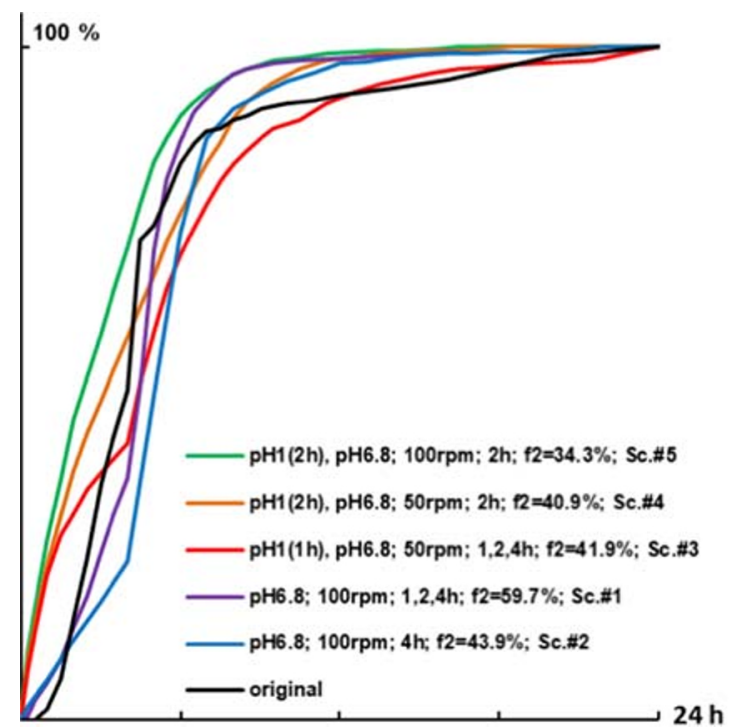

b) C-t profiles

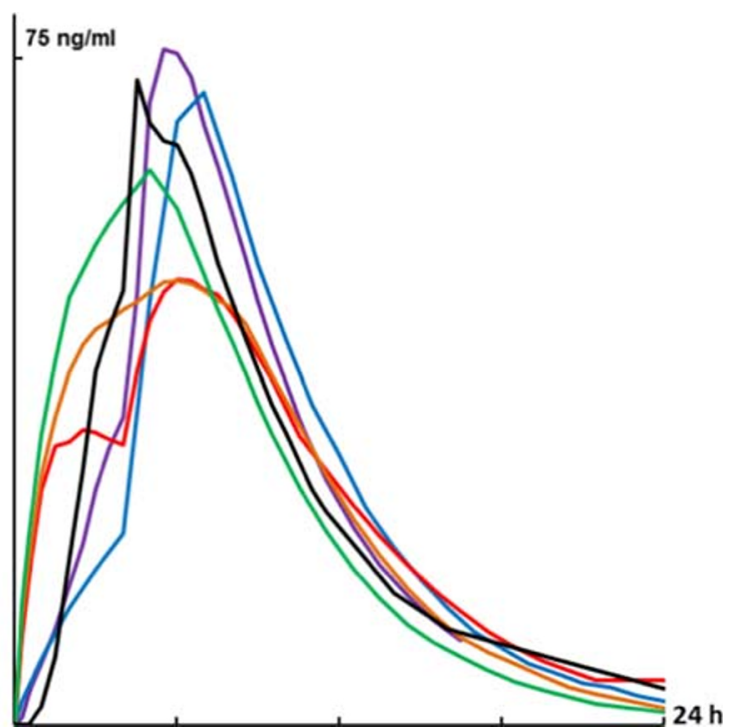

Fig. 3 (a) Dissolution profiles upon consequent stress application after I, 2 and $4 \mathrm{~h}$ during dissolution in $0.1 \mathrm{~N} \mathrm{HCl}$ and/or phosphate buffer solution pH 6.8 and stirring speed 50 or $100 \mathrm{rpm}$ in comparison with deconvoluted original C-t profile of Seroquel ${ }^{\circledR}$ XR $50 \mathrm{mg}$. (b) convoluted profiles at respective dissolution condition in comparison with the original C-t profile. SD has been waived for clarity of graphs.

with a force of approximately $1.9 \mathrm{~N}(16)$ and $1.2 \mathrm{~N}(17)$, respectively. The mechanical stress was applied at 1,2 and $4 \mathrm{~h}$ to cover time range when tablets can be affected by stomach/pyloric or upper intestinal contractions at fasting conditions. For some investigated products, namely, Glucophage ${ }^{\circledR}$ XR, Alfuzosin-ratiopharm ${ }^{\circledR}$ uno and Tromphyllin ${ }^{\circledR}$ retard dissolutions profiles were almost unchanged when subjected to $2 \mathrm{~N}$ mechanical loading after 1 , 2 or $4 \mathrm{~h}$ during dissolution test. This robustness was, probably, the reason for relatively low $\mathrm{T}_{\max }$ variability in vivo (Table III).

Vice versa, for Seroquel ${ }^{\circledR}$ XR and Preductal ${ }^{\circledR}$ MR, the effect of mechanical stress was considerable being more pronounced when applied late (e.g. $4 \mathrm{~h}$ ). This is because hydrophilic matrix tablets become softer upon swelling over time. Different robustness of investigated products can be explained by their formulations. Robust formulations contain hypromellose of higher molecular weight and content more than $20 \%$ $w / w$ which allows the formation of gel with sufficient gel strength at the gel-solution interface over a long time period.

Trying to mimic biorelevant conditions, repeatable mechanic stress events need to be considered. This was investigated on the product most susceptible to mechanical stress in this study, namely, Seroquel ${ }^{\circledR}$ XR. Because of the markable $\mathrm{pH}$-dependent solubility of quetiapine fumarate, the dissolution of Seroquel ${ }^{\circledR}$ XR was performed, optionally, in $0.1 \mathrm{~N}$ hydrochloric acid solution in first hour before changed to phosphate buffer solution $\mathrm{pH}$ 6.8. Due to application of repeatable stress in the time range $1-4 \mathrm{~h}, \mathrm{C}$-t profiles became closer in the shape to the original (Fig. 3) which was, most likely, predetermined repeatable stomach and intestinal stress.
Unfortunately, none of the individual dissolution scenarios described satisfactorily the original profile of Seroquel ${ }^{\mathrm{X}} \mathrm{XR}$ $50 \mathrm{mg}$ tablets. Therefore, convoluted dissolution profiles (scenarios) were combined in different proportions, averaged, and compared with the original C-t profile (Fig. 4, Table II).

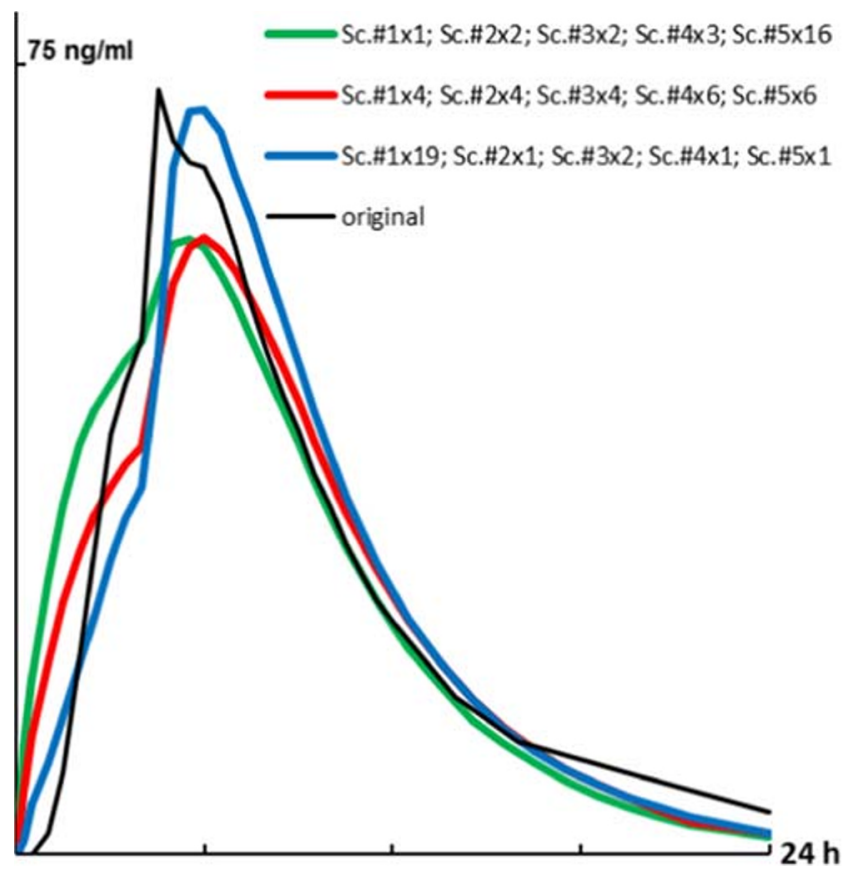

Fig. 4 Predicted C-t profiles (weighted geometrical average of different release scenarios - Table III) in comparison with the original C-t profile of Seroquel ${ }^{\circledR}$ XR $50 \mathrm{mg}$. 
Table II Summary of Dissolution Profiles of Seroquel ${ }^{\circledR}$ XR $50 \mathrm{mg}$ at Different Dissolution Conditions

\begin{tabular}{|c|c|c|c|c|}
\hline \multicolumn{3}{|l|}{ Dissolution conditions } & \multirow[t]{2}{*}{$f 2, \%$} & \multirow[t]{2}{*}{ Scenario } \\
\hline Medium pH & Stirring speed, rpm & Stress application after & & \\
\hline $\mathrm{pH} 6.8$ & 100 & $\mathrm{I}, 2$ and $4 \mathrm{~h}$ & 59.7 & Sc. \# I \\
\hline $\mathrm{pH} 6.8$ & 100 & $4 \mathrm{~h}$ & 43.9 & Sc. \#2 \\
\hline $\mathrm{pH}$ । (I h), pH 6.8 & 50 & $\mathrm{l}, 2$ and $4 \mathrm{~h}$ & 41.9 & Sc. \#3 \\
\hline $\mathrm{pH}$ । (2 h), pH 6.8 & 50 & $2 \mathrm{~h}$ & 40.9 & Sc. \#4 \\
\hline $\mathrm{pH} 6.8$ & 100 & $2 \mathrm{~h}$ & 36.8 & n.a. \\
\hline $\mathrm{pH} 6.8$ & 150 & no stress & 35.8 & n.a. \\
\hline $\mathrm{pH} 6.8$ & 100 & $\mathrm{I} h$ & 34.6 & n.a. \\
\hline $\mathrm{pH}$ । (2 h), pH 6.8 & 100 & $2 \mathrm{~h}$ & 34.3 & Sc. \#5 \\
\hline $\mathrm{pH} 1.0$ & 100 & $\mathrm{I}, 2$ and $4 \mathrm{~h}$ & 29.5 & n.a. \\
\hline $\mathrm{pH} 6.8$ & 100 & no stress & 27.7 & n.a. \\
\hline
\end{tabular}

n.a. not applied

Similarity factor ( $f 2$ ) compares the dissolution profile under respective conditions and deconvoluted original profile of Seroquel $\mathbb{R} \times \mathrm{R} 50 \mathrm{mg}$

The shape of all these profiles was closer to the published original ones. Some shape similarities, including the burst between 4 and 5 h, probably, due to stress-events in GI-tract, were also observed in other bioequivalence trials with Seroquel ${ }^{\circledR}$ XR tablets - $50 \mathrm{mg}(31,40,42)$, - $200 \mathrm{mg}$ (43) and - $300 \mathrm{mg}$ (41). However, a perfect matching of burst times barely possible because in vivo profiles are always representing the average of particular studies with a limited number of subjects and very high intra/interindividual variability. Insight into individual profiles for Seroquel® XR $300 \mathrm{mg}$ reveals that the burst can occur at 2, 3, 4, 5, 6 or even $10 \mathrm{~h}$ (27). In general, the variations of $\mathrm{T}_{\max }$ in vivo for products susceptible mechanical stress were more pronounced in comparison with stress-resistant e.g. Glucophage ${ }^{\circledR} \mathrm{XR}$ (Table III). Thus, for establishing IVIVC of oral dosage forms susceptible to mechanical stress, a comparison of the deconvoluted individual in vivo profiles with individual in vitro profiles of different release scenarios would be preferable. Further, a set of in vitro scenarios in different proportions can be used to achieve averaged profiles.

\section{CONCLUSION}

Different marketed products formulated as swellable/ erodible matrix tablets were investigated in terms of robustness against biorelevant mechanical stress. As robust formulations, Glucophage ${ }^{\circledR}$ XR $500 \mathrm{mg}$, Alfuzosinratiopharm $\AA$ uno $10 \mathrm{mg}$ or Tromphyllin $\AA$ retard $300 \mathrm{mg}$ were identified. These formulations had relatively low interindividual variability and a correlation of in vitro profiles generated with conventional dissolution tests with averaged in vivo profiles can be established. For formulations susceptible to mechanical stress e.g. Seroquel ${ }^{\circledR}$ XR $50 \mathrm{mg}$, a pharmacopeial dissolution test at the paddle speeds 50 vs. 150 rpm would give roughly an insight into robustness of matrix tablets against gastrointestinal mechanical stress. The IVIVC would be more successful if deconvoluted individual in vivo profiles were compared with in vitro profiles generated with different scenarios of release including the mechanical stress.

Table III $T_{\max }$ Variability Sourced from Single-Dose Bioequivalence Trails at Fasten Conditions

\begin{tabular}{|c|c|c|c|c|}
\hline API & Product & Subjects number & $\begin{array}{l}\mathrm{T}_{\max }(\mathrm{h}) \pm \mathrm{SD} \\
\text { (range) }\end{array}$ & Ref. \\
\hline \multirow[t]{2}{*}{ Metformin hydrochloride } & Glucophage ${ }^{\circledR}$ XR, 500 mg & 18 & $4.4 \pm 0.7$ & (30) \\
\hline & Glucophage ${ }^{\circledR}$ XR, 750 mg & 78 & $3.8 \pm 1.2$ & (38) \\
\hline \multirow[t]{2}{*}{ Trimetazidine dihydrochloride } & Preductal $₫$ MR, 35 mg & 8 & $3 \pm 1.5$ & (32) \\
\hline & & 24 & $3.2 \pm 1.3$ & (39) \\
\hline \multirow[t]{4}{*}{ Quetiapine fumarate } & Seroquel ${ }^{\circledR} \times \mathrm{R}, 300 \mathrm{mg}$ & 24 & $5.0(2.5-10)$ & $(27)$ \\
\hline & & 24 & $5.0(0.9-20)$ & $(40)$ \\
\hline & Seroquel ${ }^{\circledR}$ XR, 200 mg & 18 & $5.6 \pm 2.0$ & $(4 I)$ \\
\hline & Seroquel $\circledast$ XR, 50 mg & $\geq 12$ & 6.0 & $(3 I)$ \\
\hline
\end{tabular}




\section{FUNDING}

Open Access funding enabled and organized by Projekt DEAL.

Open Access This article is licensed under a Creative Commons Attribution 4.0 International License, which permits use, sharing, adaptation, distribution and reproduction in any medium or format, as long as you give appropriate credit to the original author(s) and the source, provide a link to the Creative Commons licence, and indicate if changes were made. The images or other third party material in this article are included in the article's Creative Commons licence, unless indicated otherwise in a credit line to the material. If material is not included in the article's Creative Commons licence and your intended use is not permitted by statutory regulation or exceeds the permitted use, you will need to obtain permission directly from the copyright holder. To view a copy of this licence, visit http://creativecommons.org/licenses/by/4.0/.

\section{REFERENCES}

1. Abrahamsson B, McAllister M, Augustijns P, Zane P, Butler J, Holm R, et al. Six years of progress in the oral biopharmaceutics area - a summary from the IMI OrBiTo project. Eur J Pharm Biopharm. 2020;152:236-47. https://doi.org/10.1016/j.ejpb. 2020.05.008.

2. Garbacz G, Kandzi A, Koziolek M, Mazgalski J, Weitschies W. Release characteristics of quetiapine fumarate extended release tablets under biorelevant stress test conditions. AAPS PharmSciTech. 2014;15(1):230-6. https://doi.org/10.1208/s12249-013-0050-2.

3. Garbacz G, Klein S. Dissolution testing of oral modified-release dosage forms. J Pharm Pharmacol. 2012;64(7):944-68. https:// doi.org/10.1111/j.2042-7158.2012.01477.x.

4. Garbacz G, Klein S, Weitschies W. A biorelevant dissolution stress test device - background and experiences. Expert Opin Drug Deliv. 2010;7(11):1251-61. https://doi.org/10.1517/17425247.2010. 527943.

5. Garbacz G, Rappen GM, Koziolek M, Weitschies W. Dissolution of mesalazine modified release tablets under standard and biorelevant test conditions. J Pharm Pharmacol. 2015;67(2):199-208. https://doi.org/10.1111/jphp.12332.

6. Koziolek M, Gorke K, Neumann M, Garbacz G, Weitschies W. Development of a bio-relevant dissolution test device simulating mechanical aspects present in the fed stomach. Eur J Pharm Sci. 2014;57:250-6. https://doi.org/10.1016/j.ejps.2013.09.004.

7. Burke MD, Kalantzi L, Parr AF, inventors; Google Patents, assignee. Pharmaceutical analysis apparatus and method patent US20100126287A1. 2010.

8. Bellmann S, Lelieveld J, Gorissen T, Minekus M, Havenaar R. Development of an advanced in vitro model of the stomach and its evaluation versus human gastric physiology. Food Res Int. 2016;88:191-8. https://doi.org/10.1016/j.foodres.2016.01.030.

9. Gao Z. In vitro dissolution testing of gelatin capsules with applied mechanical compression-a technical note. AAPS PharmSciTech. 2017;18(1):231-7. https://doi.org/10.1208/s12249-016-0506-2.

10. Gao Z, Ngo C, Ye W, Rodriguez JD, Keire D, Sun D, et al. Effects of dissolution medium $\mathrm{pH}$ and simulated gastrointestinal contraction on drug release from Nifedipine extended-release tablets. J
Pharm Sci. 2019;108(3):1189-94. https://doi.org/10.1016/j. xphs.2018.10.014.

11. Vardakou M, Mercuri A, Barker SA, Craig DQ, Faulks RM, Wickham MS. Achieving antral grinding forces in biorelevant in vitro models: comparing the USP dissolution apparatus II and the dynamic gastric model with human in vivo data. AAPS PharmSciTech. 2011;12(2):620-6. https://doi.org/10.1208/ s12249-011-9616-z.

12. Takieddin M, Fassihi R. A novel approach in distinguishing between role of hydrodynamics and mechanical stresses similar to contraction forces of GI tract on drug release from modified release dosage forms. AAPS PharmSciTech. 2015;16(2):278-83. https:// doi.org/10.1208/s12249-014-0225-5.

13. Kambayashi A, Dressman JB. A novel in vivo predictive dissolution testing coupled with a modeling and simulation for hydrogel matrix monolithic extended release oral dosage forms. Eur J Pharm Sci. 2019;138:105044. https://doi.org/10.1016/j.ejps.2019.105044.

14. Fernandes R, Gracias DH. Toward a miniaturized mechanical surgeon. Mater Today. 2009;12(10):14-20. https://doi.org/10. 1016/S1369-7021(09)70272-X.

15. Kamba M, Seta Y, Kusai A, Nishimura K. Evaluation of the mechanical destructive force in the stomach of dog. Int J Pharm. 2001;228(1-2):209-17. https://doi.org/10.1016/s0378-5173(01) 00844-4.

16. Kamba M, Seta Y, Kusai A, Ikeda M, Nishimura K. A unique dosage form to evaluate the mechanical destructive force in the gastrointestinal tract. Int J Pharm. 2000;208(1-2):61-70. https:// doi.org/10.1016/s0378-5173(00)00552-4.

17. Kamba M, Seta Y, Kusai A, Nishimura K. Comparison of the mechanical destructive force in the small intestine of dog and human. Int J Pharm. 2002;237(1-2):139-49. https://doi.org/10. 1016/s0378-5173(02)00043-1.

18. McConnell EL, Fadda HM, Basit AW. Gut instincts: explorations in intestinal physiology and drug delivery. Int J Pharm. 2008;364(2): 213-26. https://doi.org/10.1016/j.jpharm.2008.05.012.

19. Weitschies W, Kosch O, Monnikes H, Trahms L. Magnetic marker monitoring: an application of biomagnetic measurement instrumentation and principles for the determination of the gastrointestinal behavior of magnetically marked solid dosage forms. Adv Drug Deliv Rev. 2005;57(8):1210-22. https://doi.org/10.1016/j.addr. 2005.01.025.

20. Koziolek M, Kostewicz E, Vertzoni M. Physiological considerations and in vitro strategies for evaluating the influence of food on drug release from extended-release formulations. AAPS PharmSciTech. 2018;19(7):2885-97. https://doi.org/10.1208/ s12249-018-1159-0.

21. Khosla R, Davis S. The effect of tablet size on the gastric emptying of non-disintegrating tablets. Int J Pharm. 1990;62(2-3):R9-R11.

22. Podczeck F, Course NC, Newton JM, Short MB. The influence of non-disintegrating tablet dimensions and density on their gastric emptying in fasted volunteers. J Pharm Pharmacol. 2007;59(1): 23-7. https://doi.org/10.1211/jpp.59.1.0004.

23. Suarez-Sharp S, Cohen M, Kesisoglou F, Abend A, Marroum P, Delvadia $\mathrm{P}$, et al. Applications of clinically relevant dissolution testing: workshop summary report. AAPS J. 2018;20(6):93. https:// doi.org/10.1208/s12248-018-0252-3.

24. Nguyen MA, Flanagan T, Brewster M, Kesisoglou F, Beato S, Biewenga J, et al. A survey on IVIVC/IVIVR development in the pharmaceutical industry - past experience and current perspectives. Eur J Pharm Sci. 2017;102:1-13. https://doi.org/10.1016/j.ejps. 2017.02.029.

25. Martinez MN, Amidon GL. A mechanistic approach to understanding the factors affecting drug absorption: a review of fundamentals. J Clin Pharmacol. 2002;42(6):620-43. https://doi.org/10. $1177 / 00970002042006005$. 
26. Marston SA, Polli JE. Evaluation of direct curve comparison metrics applied to pharmacokinetic profiles and relative bioavailability and bioequivalence. Pharm Res. 1997;14(10):1363-9. https://doi. org/10.1023/a:1012160419520.

27. Estevez-Carrizo FE, Parrillo S, Ercoli MC, Estevez-Parrillo FT. Single-dose relative bioavailability of a new quetiapine fumarate extended-release formulation: a postprandial, randomized, openlabel, two-period crossover study in healthy Uruguayan volunteers. Clin Ther. 2011;33(6):738-45. https://doi.org/10.1016/j. clinthera.2011.05.002.

28. Guidance for Industry SUPAC-MR: Modified Release Solid Oral Dosage Forms. FDA (CDER); 1997.

29. Guideline on quality of oral modified release products. EMA (CHMP); 2014.

30. IVAX_Pharmaceuticals. Approval Package for Metformin HCl Extended-release Tablets, 500mg (ANDA 76-545). In: CDER_FDA, editor. USA2003. p. 154.

31. Fachinformation. Rote Liste2019.

32. Chowdhury MM, Ullah MA, Al Maruf A, Islam MS, Ahmed MU, Shohag $\mathrm{H}$, et al. Validation and optimization of a simple RP-HPLC method for determination of Trimetazidine in human serum and its application in a pharmacokinetic study with healthy Bangladeshi male volunteers. Dhaka Univ J Pharm Sci. 2011;10(2):71-8. https://doi.org/10.3329/dujps.v10i2.11783.

33. Wagner JG. Estimation of theophylline absorption rate by means of the Wagner-Nelson equation. J Allergy Clin Immunol. 1986;78(4 Pt 2):681-8. https://doi.org/10.1016/0091-6749(86)90046-1.

34. Gohel M, Delvadia R, Parikh D, Zinzuwadia M, Soni C, Sarvaiya $\mathrm{K}$, et al. Simplified mathematical approach for back calculation in Wagner-Nelson method: applications in in vitro and in vivo correlation (IVIVC) and formulation development work. Pharm Rev. 2005;3(2):1-8.

35. Dressman J. Pharmaceutical dissolution testing: Taylor \& Francis; 2005.

36. Goldoozian $\mathrm{R}$ et al. In vitro-in vivo correlation (IVIVG) for swellable matrix tablets with different gel strength. Proc. 10th World Meeting
Pharmaceutics, Biopharmaceutics and Pharmaceutical Technology. Glasgow, UK. 2016.

37. Kostewicz ES, Abrahamsson B, Brewster M, Brouwers J, Butler J, Carlert $\mathrm{S}$, et al. In vitro models for the prediction of in vivo performance of oral dosage forms. Eur J Pharm Sci. 2014;57:342-66. https://doi.org/10.1016/j.ejps.2013.08.024.

38. Idkaidek N, Arafat T. Metformin IR versus XR Pharmacokinetics in Humans. J Bioequiv Availab. 2011;03(10), https://doi.org/10. 4172/jbb.1000092.

39. Chowdhury MM, Ullah MA, Iqbal N, Al Maruf A, Shohag MH, Harun S, et al. Relative bioavailability and pharmacokinetic study of two trimetazidine modified release formulations in healthy Bangladeshi male volunteers. Arzneimittelforschung. 2011;61(7): 393-8. https://doi.org/10.1055/s-0031-1296217.

40. Bui K, Earley W, Nyberg S. Pharmacokinetic profile of the extended-release formulation of quetiapine fumarate (quetiapine XR): clinical implications. Curr Med Res Opin. 2013;29(7):81325. https://doi.org/10.1185/03007995.2013.794774.

41. Huang X, Zhang S, Ma Y, Yang H, He C, Tian R, et al. Bioequivalence of two quetiapine extended release tablets in Chinese healthy volunteers under fasting and fed conditions and effects of food on pharmacokinetic profiles. Drug Des Devel Ther. 2019;13:255-64. https://doi.org/10.2147/DDDT.S182965.

42. Astra_Zeneca. Seroquel SR® Clinical Pharmacological and Biopharmaceutical Review(s). Original NDA (New Formulation). 2006 7/17/06. Contract No.: NDA \#22-047.

43. Lee JS, Hong DY, Kim ES, Lee HG. Improving the water solubility and antimicrobial activity of silymarin by nanoencapsulation. Colloids Surf B Biointerfaces. 2017;154:171-7. https://doi.org/ 10.1016/j.colsurfb.2017.03.004.

Publisher's Note Springer Nature remains neutral with regard to jurisdictional claims in published maps and institutional affiliations. 